\title{
COMPOSIÇÃO FLORÍSTICA E FITOSSOCIOLÓGICA DO MANGUEZAL DA ZONA PORTUÁRIA DE SÃO LUÍS, MARANHÃO, BRASIL
}

\section{FLORISTIC AND PHYTOSOCIOLOGICAL COMPOSITION OF THE PORT AREA MANGORVES IN SÃO LUÍS, MARANHÃO, BRAZIL}

\author{
Alexandre Leão Gonçalves ${ }^{1}$, Vanessa Maria Silva da Cruz $^{2}$, Jamerson Rodrigo dos Prazeres \\ Campos $^{3}$, Deivison Venicio Souza ${ }^{4}$ \\ 1, 2, 3, 4 Universidade Federal do Pará, Altamira, Pará, Brasil - eng.alexandregoncalves@outlook.com, \\ vanessa.msc@hotmail.com,jam_rod002@yahoo.com.br\&souzaflorestal@gmail.com
}

\begin{abstract}
RESUMO
Os manguezais estão entre os ecossistemas mais vulneráveis e passíveis de degradação, necessitando-se de estudos que auxiliem na sua compreensão. Assim, o objetivo deste estudo foi descrever as características florísticas e fitossociológicas do manguezal da zona portuária de São Luís - MA. Foram instaladas 20 parcelas medindo $20 \mathrm{~m} \times 20$ $\mathrm{m}\left(400 \mathrm{~m}^{2}\right)$, por meio de uma amostragem inteiramente aleatória, onde foram quantificados todos os indivíduos arbóreos com diâmetro a 1,3 m maior ou igual a $5 \mathrm{~cm}$, tendo o auxílio de uma fita métrica, ao passo que a altura das árvores foi estimada por meio do método de superposição de ângulos. Os indivíduos inventariados foram agrupados em classes de diâmetro e de altura, e calculou-se os parâmetros fitossociológicos das espécies. Na distribuição diamétrica, a maioria dos indivíduos se enquadrou nas menores classes, enquanto na distribuição de altura, a maior parte se concentrou nas classes intermediárias. Quantificou-se 365 indivíduos distribuídos em três famílias, três gêneros e quatro espécies, dentre as quais Rhizophora mangle apresentou o maior número de indivíduos (321) e os maiores valores em todos os parâmetros fitossociológicos, com valor de importância de 81,49. Dessa maneira, constatou-se que $R$. mangle é a espécie mais importante para a área investigada e, apesar dessa predominância, a vegetação é estruturalmente heterogênea.
\end{abstract}

PALAVRAS-CHAVE: Estrutura da vegetação, Formação fluviomarinha, Fragilidade ecológica.

\begin{abstract}
The mangroves are among the most vulnerable and degradable ecosystems, requiring researches to aid their understanding. Therefore, this research aims to describe the floristic and phytosociological characteristics of portuary

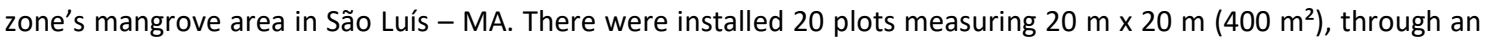
entirely random sampling, where were quantified all the individuals with diameter at $1.3 \mathrm{~m} \geq 5 \mathrm{~cm}$, having the aid of a tape measure, while the tree heights were estimated through the angle superposition method. The inventoried individuals were grouped into diameter and height classes, and the phytosociological parameters of the species were calculated. In the diametric distribution, most of the individuals fitted into the smaller classes, and in the height distribution the majority was concentrated in the intermediate classes. A number of 365 individuals were quantified and divided in three families, three genera, and four species, among which Rhizophora mangle presented the largest number of individuals (321) and highest values in all phytosociological parameters, with importance valor equal to 81.49. Thus, it was verified that $R$. mangle is the most important species for the investigated area, and despite its predominance, the vegetation is structurally heterogeneity.
\end{abstract}

KEYWORDS: Structure of vegetation, Fluvio-marine formation, Ecological fragility. 


\section{INTRODUÇÃO}

Os manguezais são ecossistemas de regiões tropical e subtropical, em que sua vegetação pode ser descrita como uma autêntica floresta costeira (SANTOS et al., 2012; LONDE et al., 2013), com estrutura de espécies vegetais fortemente adaptadas às diferenças topográficas e geomorfológicas, bem como às flutuações salinas e amplitudes de marés (OLIVEIRA \& TOGNELLA, 2014).

$O$ ambiente desse ecossistema caracteriza-se por apresentar solo encharcado e com variação de salinidade, que ocorre em função do regime de marés e chuvas (BLOTTA et al., 2016). Segundo Londe et al. (2013), os manguezais possuem quatro compartimentos que são interdependentes, mas com características intrínsecas individuais: água, solo, flora e fauna.

Dessa maneira, os manguezais transmitem a perfeita integração e o equilíbrio dinâmico entre os seus componentes do ponto de vista ecológico (LONDE et al., 2013). Em razão de ser um ambiente costeiro, torna-se o habitat de diversas populações e possui condições ideais para a reprodução de várias espécies de peixes, crustáceos e moluscos, sendo considerado um dos ambientes naturais mais produtivos do Brasil (BERNINI et al., 2014; BLOTTA et al., 2016).

Em se tratando da vegetação, nota-se que há baixa diversidade, uma vez que poucas espécies conseguem se adaptar às condições de maré, salinidade, substrato inconsolidado e pouco oxigenado (OLIVEIRA \& TOGNELLA, 2014). Esses fatores exercem influência na formação da vegetação e, geralmente, as espécies vegetais de mangue estão distribuídas em zonas em relação à linha d'água, constituindo em uma fisionomia peculiar (ALMEIDA et al., 2014).

De acordo com Martins et al. (2011), as árvores que compõem a vegetação inundada são predominantemente lenhosas típicas, geralmente dos gêneros Rhizophora, Avicennia e Laguncularia. Apesar da baixa diversidade vegetal, esses locais são dotados de grande complexidade funcional, tornando difícil a padronização de conceitos ecológicos sobre os mesmos (SANTOS et al., 2012).

Dentre os ecossistemas costeiros, o manguezal é considerado no contexto atual o mais vulnerável e passível a degradação, devido às atividades antrópicas concentradas no seu entorno (PARAGUASSU \& SILVA, 2007). Aliado a isso, verifica-se a necessidade de estudos que auxiliem na compreensão desses ambientes, como a caracterização estrutural da vegetação, que serve para avaliar a resposta das espécies às condições ambientais inóspitas, e aos processos de alteração do meio natural
(BERNINI \& REZENDE, 2010; MARTINS et al., 2011).

Diante desse cenário, o objetivo do presente estudo foi descrever as características florísticas e fitossociológicas do manguezal da zona portuária de São Luís no estado do Maranhão.

\section{MATERIAL E MÉTODOS}

O estudo foi desenvolvido no manguezal da região portuária do município de São Luís, capital do estado do Maranhão. Observando-se por um transecto em linha reta, a área está localizada a aproximadamente $7 \mathrm{~km}$ de distância do Terminal Portuário do Itaqui.

A área estudada apresenta vegetação com influência fluviomarinha, em razão de localizar-se em zona de convergência e mistura das águas do Oceano Atlântico Sul com as águas continentais do caudal de montante dos rios Itapecuru e Munim, que formam a baía de São José a Leste, e Mearim e Pindaré que formam a baía de São Marcos a Oeste (PMSL, 2011; IBGE, 2012).

De acordo com a classificação de Köppen, o clima da região enquadra-se no tipo úmido $\mathrm{B} 2$, com ocorrência do subtipo a', tendo déficit hídrico moderado no verão do tipo $S$, megatérmico tipo $A^{\prime}$, com evapotranspiração potencial de verão de 25,2\% (MARTINS \& OLIVEIRA, 2011). A temperatura média anual é de $26^{\circ} \mathrm{C}$, com índice pluviométrico anual na ordem de $1.400 \mathrm{~mm}$ (INMET, 2016).

A amostragem constituiu-se na instalação de 20 parcelas de $20 \mathrm{~m} \times 20 \mathrm{~m}\left(400 \mathrm{~m}^{2}\right)$ alocadas ao longo do mangue, por meio do processo de amostragem inteiramente aleatório. A disposição das parcelas amostrais na área está apresentada na Figura 1.

Em cada parcela, foram identificados e mensurados todos os indivíduos arbóreos com circunferência a $1,3 \mathrm{~cm}$ do solo (CAP) maior ou igual a $15 \mathrm{~cm}$, tendo o auxílio de uma fita métrica. Posteriormente, essas medidas foram convertidas em diâmetro a 1,3 m (DAP) conforme a metodologia de Soares et al. (2011).

A altura das árvores foi estimada por meio do método de superposição de ângulos, que consiste nos seguintes passos: (1) encostar uma baliza de tamanho conhecido na árvore a ser medida; (2) operador deve segurar com o braço estendido um lápis ou qualquer objeto com característica similar e deslocar-se até que os extremos do lápis coincidam com os da baliza; (3) sobrepor a base do lápis com o extremo superior da baliza; (4) repetir e contabilizar a ação de sobreposição até o ápice da árvore; e (5) a altura da árvore será a soma dos ângulos superpostos (SILVA \& PAULA NETO, 1979; IMAÑA ENCINAS et al., 2014). 


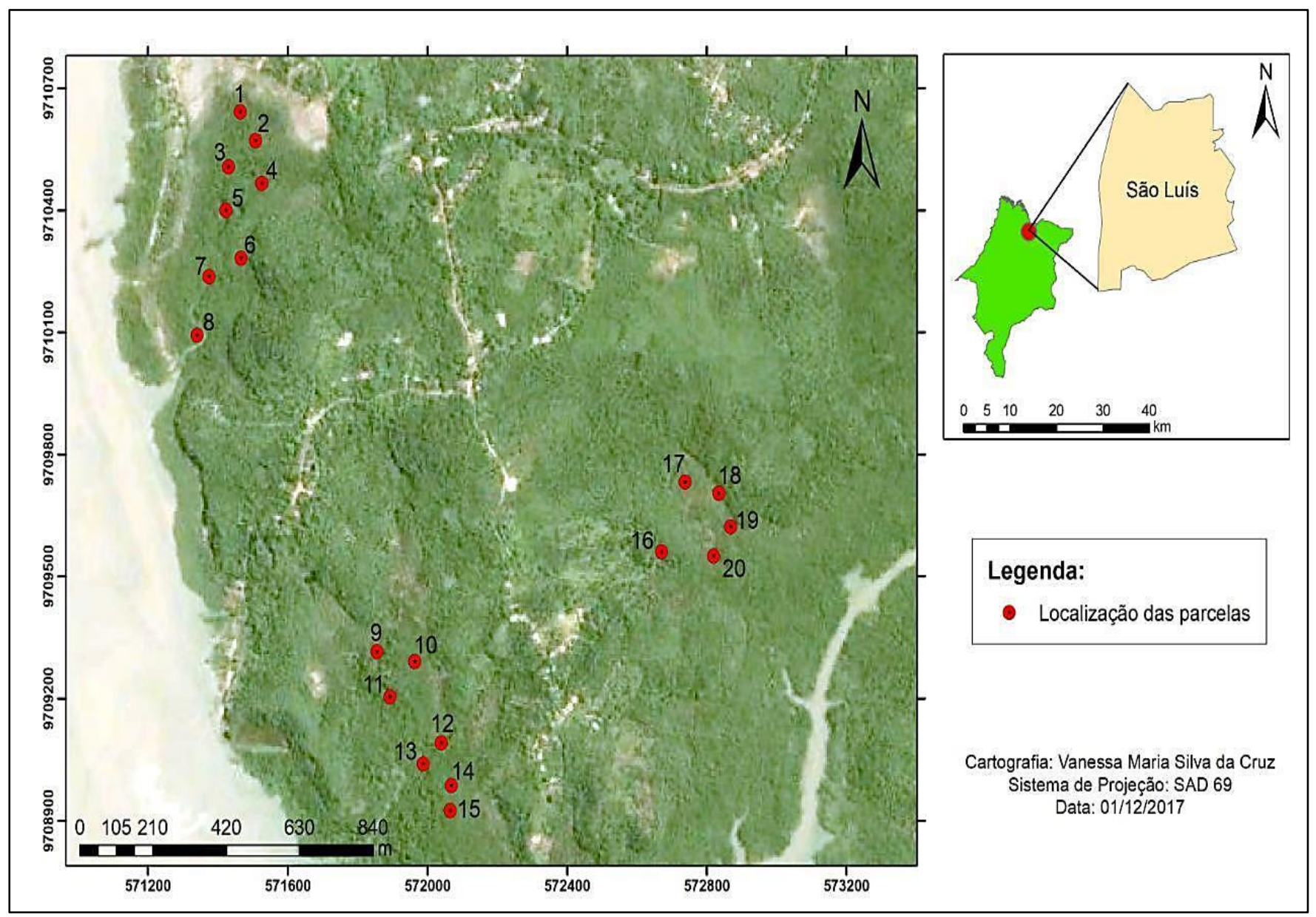

Figura 1. Alocação das parcelas amostrais no manguezal da zona portuária de São Luís - MA.

Posteriormente, todos os indivíduos inventariados foram agrupados em classes de diâmetro e de altura correspondentes ao mensurado em campo.

A identificação das espécies foi feita em campo por um engenheiro florestal experiente na composição da vegetação da região. No caso de indivíduos que não puderam ser identificados in loco, foi recolhido material botânico e encaminhado para o reconhecimento por um botânico taxonomista. Adotou-se o APG III (2009) como sistema taxonômico para este estudo.

Para a observação dos aspectos estruturais, calculou-se os parâmetros fitossociológicos das espécies: frequência absoluta e relativa, densidade absoluta e relativa, dominância absoluta e relativa e valor de importância, seguindo os métodos de Mueller-Dombois \& Ellenberg (1974). Os cálculos e o processamento dos dados foram executados por meio do software Microsoft Excel versão 2013.

\section{RESULTADOS E DISCUSSÃO}

De maneira geral, as árvores existentes no manguezal investigado possuem troncos retorcidos, copa pouco densa, raízes pneumatóforas, que auxiliam na realização de trocas gasosas com $\mathrm{o}$ ambiente, e apresentam crescimento baixo em diâmetro e médio em altura (Figura 2). Essas características conferem peculiaridade fisionômica própria desse ecossistema, principalmente, quando comparado à fisionomia das florestas de terra firme.

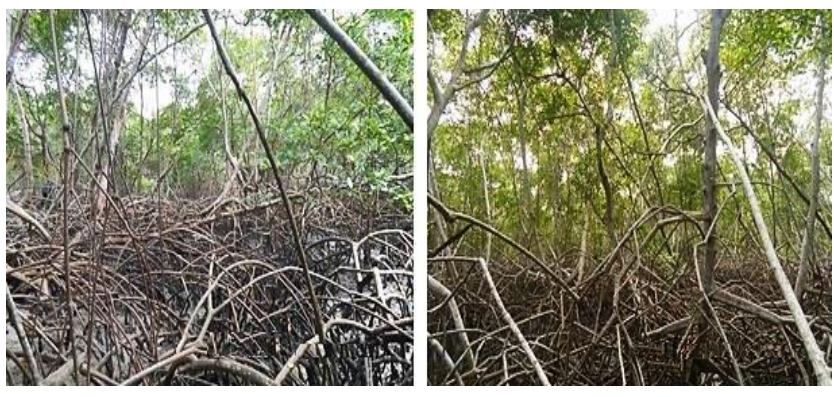

Figura 2. Fisionomia da vegetação no manguezal da zona portuária de São Luís - MA.

A fisionomia da vegetação existente no manguezal da zona portuária de São Luís é semelhante às outras relatadas em diversos estudos, como: Londe et al. (2013) 
no mangue do rio Piraquê-Açu, litoral Norte do estado do Espírito Santo; Almeida et al. (2014) no manguezal do rio Tabatinga, em Suape, estado do Pernambuco; e Silva et al. (2016) na zona estuaria do rio Miriri, estado da Paraíba. Nesse sentindo, avalia-se que os ambientes de manguezal apresentam semelhanças em relação à estrutura fisionômica, mesmo quando estão localizados em regiões distintas.

O estudo quantificou o total de 365 indivíduos distribuídos em três famílias botânicas, três gêneros e quatro espécies. Londe et al. (2013) inventariaram 307 indivíduos e oito espécies, sendo três típicas do mangue (pertencentes a três famílias e três gêneros) e cinco de terra firme. Devido à ausência de material fértil, apenas uma espécie de terra firme pôde ser identificada precisamente por esses autores.

Em um estudo comparativo entre os manguezais do Canal de Bertioga - SP e do estuário da Barra do Rio UnaPeruíbe - SP, Blotta et al. (2016) verificaram a ocorrência de três famílias botânicas, três gêneros e três espécies. $O$ mesmo resultado foi obtido por Madi et al. (2016), quando investigaram dois manguezais no estado do Paraná. Ambos os estudos corroboram com os resultados desta pesquisa.

Apesar de apresentar uma quantidade expressiva de indivíduos, os estudos realizados no ecossistema manguezal em diferentes regiões do Brasil têm apontado para uma baixa variedade de espécies vegetais nesses ambientes (MARTINS et al., 2011; SANTOS et al., 2012; OLIVEIRA \& TOGNELLA, 2014; ALMEIDA et al., 2014; BERNINI et al., 2014; SILVA et al., 2016; LOURENÇO et al., 2017).

Não obstante, ainda com a baixa diversidade vegetal, diversas pesquisas têm ressaltado a importância desse ecossistema, que possui complexidade e cumpre papel fundamental no equilíbrio ecológico das regiões costeiras (PARAGUASSU \& SILVA, 2007). Assim, a quantidade de indivíduos inventariados de cada espécie identificada no manguezal da região portuária de São Luís - MA pode ser observada na Tabela 1.

No estado do Maranhão, é comumente encontrado manguezais formados apenas por espécies do gênero Rhizophora (IBGE, 2012). A maior ocorrência de Rhizophora mangle também foi relatada por Paraguassu \& Silva (2007), Santos et al. (2012), Silva et al. (2016) e Lourenço et al. (2017). Enquanto Londe et al. (2013) e Bernini et al. (2014) identificaram Laguncularia racemosa como a espécie mais frequente.
Tabela 1. Florística do manguezal da zona portuária de São Luís-MA.

\begin{tabular}{cccc}
\hline $\begin{array}{c}\text { Nome } \\
\text { vulgar }\end{array}$ & Espécie & Família & No \\
\hline $\begin{array}{c}\text { Mangue } \\
\text { vermelho }\end{array}$ & Rhizophora mangle L. & Rhizophoraceae & 321 \\
$\begin{array}{c}\text { Mangue } \\
\text { preto }\end{array}$ & $\begin{array}{c}\text { Avicennia schaueriana Stapf } \\
\text { \& Leechm. ex Moldenke }\end{array}$ & Acanthaceae & 29 \\
$\begin{array}{c}\text { Mangue } \\
\text { branco }\end{array}$ & $\begin{array}{c}\text { Laguncularia racemosa (L.) } \\
\text { C.F.Gaertn. }\end{array}$ & Combretaceae & 13 \\
$\begin{array}{c}\text { Mangue } \\
\text { preto/ } \\
\text { Siriúba }\end{array}$ & $\begin{array}{c}\text { Avicennia germinans (L.) L. } \\
\text { Total }\end{array}$ & Acanthaceae & 2 \\
\hline № = número de indivíduos inventariados da espécie. & 365 \\
\hline
\end{tabular}

A ocorrência das plantas dos gêneros Rhizophora e Avicennia varia de acordo com a latitude. Por outro lado, Laguncularia cresce nos locais mais altos e aparece comumente em terreno firme, sendo atingida somente pela preamar. Ambas as espécies desses gêneros estão distribuídas ao longo da faixa costeira da Amazônia, incluindo a Guiana Francesa (BEZERRA, 2005; IBGE, 2012; ALMEIDA et al., 2014).

Análogo a esse estudo, essas espécies também foram verificadas em vários estados, como: Rio de Janeiro (BERNINI et al., 2014), São Paulo (BLOTTA et al., 2016; LOURENÇO et al., 2017), Espírito Santo (LONDE et al., 2013), Bahia (PARAGUASSU \& SILVA, 2007), Sergipe (SANTOS et al., 2012), Pernambuco (ALMEIDA et al., 2014), Paraíba (SILVA et al., 2016), Santa Catarina (OLIVEIRA \& TOGNELLA, 2014) e Paraná (MADI et al., 2016). Esse fator reafirma a ampla distribuição geográfica dessas espécies ao longo da costa das regiões brasileiras.

Segundo Mochel (2011), a vegetação existente nos manguezais da Amazônia é composta por quatro gêneros e sete espécies: Rhizophora mangle, $R$. racemosa, R. harrisonii, Avicennia germinans, $A$. schaueriana, Laguncularia racemosa e Conocarpus erectus. $O$ estado do Maranhão está localizado numa área de transição entre o nordeste e a região amazônica (MARTINS \& OLIVEIRA, 2011), sendo assim, os resultados desta pesquisa corroboraram com o padrão descrito por Mochel (2011).

As árvores presentes na área investigada apresentaram DAP entre 10 e $30 \mathrm{~cm}$ (média de $15 \mathrm{~cm}$ ) e altura entre 4 e $20 \mathrm{~m}$ (média de 11,7 m). Quanto à distribuição diamétrica, observou-se que a maioria dos indivíduos se enquadrou nas menores classes. Tal relação não ocorreu na distribuição por classes de altura, em que a maior parte das árvores se concentrou nas classes intermediárias, majoritariamente na segunda maior classe (Figura 3). 

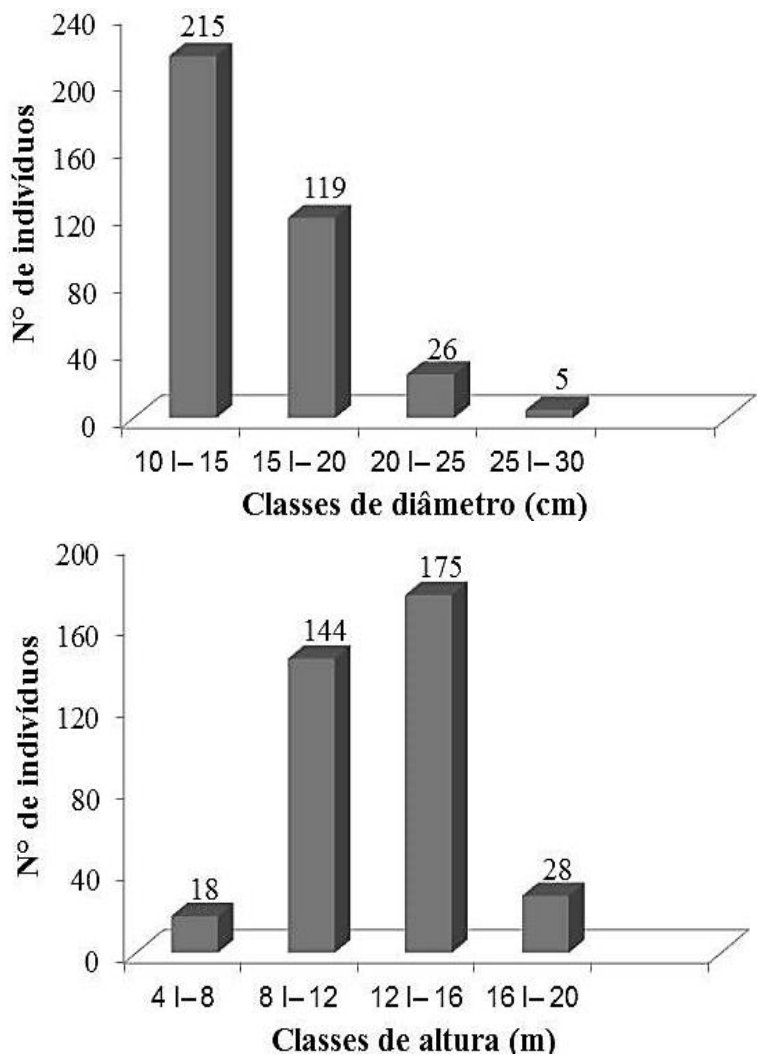

Figura 3. Distribuição dos indivíduos inventariados no manguezal da zona portuária de São Luís - MA por classes de diâmetro e altura.

Em ambos os parâmetros, Rhizophora mangle foi a espécie que alcançou os maiores valores, com DAP de 30 $\mathrm{cm}$ (média de $15 \mathrm{~cm}$ ) e altura de $20 \mathrm{~m}$ (média de $12 \mathrm{~m}$ ). Em valores médios, não houve uma única espécie predominante nos dois parâmetros, dessa maneira, destacou-se $A$. germinans com a maior média de DAP (18 $\mathrm{cm})$ e $A$. schaueriana com a maior média de altura (18,2 $\mathrm{m})$.

Ao caracterizar a estrutura de bosques de mangue no estuário do rio São Francisco, em Pacatuba e Brejo Grande - SE, Santos et al. (2012) obtiveram um resultado diferente ao desta pesquisa, em que Laguncularia racemosa foi a espécie que alcançou os maiores índices, com DAP de 33 $\mathrm{cm}$ e altura de $11,3 \mathrm{~m}$.

No manguezal do rio Benevente, em Anchieta, estado do Espírito do Santo, Petri et al. (2011) registraram $A$. schaueriana com maiores valores de DAP e altura $(126 \mathrm{~cm}$, $27 \mathrm{~m}$, respectivamente), sendo $R$. mangle exibiu o maior DAP $(33 \mathrm{~cm})$ e a maior altura $(25,5 \mathrm{~m})$, assemelhando-se ao encontrado para essa espécie no manguezal da zona portuária de São Luís - MA.

Bernini et al. (2014), investigando a fitossociologia de florestas de mangue plantadas e naturais no estuário do Rio das Ostras, Rio de Janeiro, também relataram o maior número de indivíduos nas menores classes diamétricas. $\mathrm{Na}$ floresta plantada, os autores quantificaram a maioria dos indivíduos na classe entre 1,0 e 3,0 cm, enquanto na floresta natural houve maior número na classe entre 3,1 e $6,0 \mathrm{~cm}$. Esses autores também registraram a maioria dos indivíduos nas classes intermediárias de altura, tendo a maior concentração na classe entre 6,1 e 8,0 m.

O mesmo resultado, concernente as classes de diâmetro, foi obtido no estudo realizado por Almeida et al. (2014) no manguezal do rio Tabatinga, em Suape - PE, em que a maior parte dos troncos mediram entre 2,5 e 9,9 cm de diâmetro.

De acordo com Lourenço et al. (2017), fatores naturais, como a salinidade e incidência solar, afetam a altura e a densidade do bosque a partir da área mais próxima à água. Nesse sentido, Silva et al. (2016) esclarecem que o incremento da salinidade no ambiente do manguezal faz com que a altura, o diâmetro e a área basal decresçam, em razão do amplo gasto de energia requerido para a exclusão de sal pelas raízes. Esse fator exerce influência direta na absorção de nutrientes e no balanço hídrico da planta.

Considerando que as espécies desse tipo de ambiente não atingem grandes diâmetros, pode-se inferir que os resultados desta pesquisa estão no padrão esperado para esse ecossistema. Concernente à altura, os resultados deste estudo foram discrepantes da maioria das pesquisas em manguezais (SANTOS et al., 2012; BERNINI et al., 2014), apresentando valores mais elevados.

Assim como ocorre nos diferentes ambientes de floresta, os manguezais são dinâmicos, possuem crescimento contínuo e constantemente se restabelecem e se renovam (ALMEIDA et al., 2014). Essa constante renovação pode explicar o baixo crescimento em diâmetro registrado em diversas pesquisas. De modo geral, observou-se que as espécies investem mais no crescimento em altura para se estabelecer no ambiente e dar continuidade ao seu processo de evolução e adaptação às condições inóspitas desse ecossistema.

A análise fitossociológica evidenciou que Rhizophora mangle foi a espécie com maior destaque no manguezal da zona portuária de São Luís - MA, representando mais da metade do estimado para a população em todos os parâmetros analisados (Tabela 2).

A maior ocorrência de $R$. mangle está diretamente relacionada a ampla tolerância às condições de inundação que essa espécie possui (MCKEE, 1993). Esse fator influencia significativamente para a sua maior dispersão e adaptabilidade nesses ambientes. 
Tabela 2. Análise fitossociológica da vegetação no manguezal da zona portuária de São Luís - MA

\begin{tabular}{|c|c|c|c|c|c|}
\hline \multirow[b]{2}{*}{ PF } & \multicolumn{4}{|c|}{ Espécies } & \multirow[b]{2}{*}{ Total } \\
\hline & $\begin{array}{c}R . \\
\text { mangle }\end{array}$ & $\begin{array}{c}A . \\
\text { schaueriana }\end{array}$ & $\begin{array}{c}L . \\
\text { racemosa }\end{array}$ & $\begin{array}{c}A . \\
\text { germinans }\end{array}$ & \\
\hline FA & 1,00 & 0,30 & 0,20 & 0,05 & 1,55 \\
\hline $\mathrm{FR}$ & $64,52 \%$ & $19,35 \%$ & $12,90 \%$ & $3,23 \%$ & $100 \%$ \\
\hline DA & 401,25 & 36,25 & 16,25 & 2,5 & 456 \\
\hline DR & $87,95 \%$ & $7,95 \%$ & $3,56 \%$ & $0,55 \%$ & $100 \%$ \\
\hline DoA & 0,1819 & 0,0095 & 0,0042 & 0,0021 & 0,1977 \\
\hline DoR & $91,99 \%$ & $4,81 \%$ & $2,14 \%$ & $1,06 \%$ & $100 \%$ \\
\hline VI & $81,49 \%$ & $10,70 \%$ & $6,20 \%$ & $1,61 \%$ & $100 \%$ \\
\hline
\end{tabular}

$\mathrm{PF}=$ parâmetro fitossociológico; $\mathrm{FA}=$ frequência absoluta; $\mathrm{FR}=$ frequência relativa (\%); $\mathrm{DA}=$ densidade absoluta; $\mathrm{DR}=$ densidade relativa (\%); DoA = dominância absoluta; DoR = dominância relativa (\%); e $\mathrm{VI}=$ valor de importância (\%).

Londe et al. (2013) relataram resultados diferentes ao desta pesquisa, em que $L$. racemosa foi a espécie predominante em todos os parâmetros fitossociológicos, seguida por $R$. mangle, A. schaueriana e Terminalia catappa L., respectivamente com valores de VI de 49,3\%, $22,5 \%, 14,9 \%$ e $3,4 \%$.

Os valores elevados de frequência, densidade e dominância estimados para uma população representam as espécies de maior importância, quando o levantamento em questão é a estrutura da comunidade (LAMPRECHT, 1990). Assim como para $R$. mangle neste estudo, que alcançou valores altos de frequência, densidade, dominância e, consequentemente, de VI.

É corriqueira a frequência de $R$. mangle na franja dos manguezais em contato com o estuário, em áreas que sofrem inundações pelas marés, principalmente nas proximidades das desembocaduras, sendo gradualmente substituída pelas espécies do gênero Avicennia ou $L$. racemosa na parte interior do bosque (ALMEIDA et al., 2014).

A segunda espécie mais representativa foi a $A$. schaueriana, com o segundo maior VI. Silva et al. (2016) também relataram essa espécie como a segunda de maior destaque, com valores de DR de $30 \%$ e DoR de $30,1 \%$. Por outro lado, Blotta et al. (2016) registraram A. schaueriana com a menor notabilidade dentre as três espécies identificadas em sua pesquisa, alcançando VI de 1,1\%, enquanto L. racemosa apresentou VI de $2,2 \%$ e $R$. mangle de $1,3 \%$.

Diferentemente ao que acontece com $R$. mangle, observou-se que $A$. schaueriana não forma bosques homogêneos, ocorrendo sempre em concomitância com outras espécies em maior ou menor densidade. Assim, mesmo com a representatividade de $R$. mangle, nota-se que a vegetação do mangue estudado apresenta heterogeneidade em sua estrutura.

Para Bernini \& Rezende (2010), a heterogeneidade das características estruturais das florestas está em função das variações das energias subsidiárias, como marés e ondas, nutrientes, aporte de água doce, temperatura, vento, radiação solar e precipitação. Segundo os autores, a influência de distintos tensores naturais e antrópicos atuam em diferentes escalas espacial e temporal, refletindo na maior ou menor heterogeneidade estrutural da vegetação.

\section{CONCLUSÕES}

O manguezal da zona portuária de São Luís caracterizase pela ampla ocorrência de $R$. mangle, que alcançou os maiores valores em todos parâmetros fitossociológicos, sendo a espécie mais importante para a área investigada. Apesar dessa predominância, a vegetação é estruturalmente heterogênea.

A fisionomia da vegetação e as medidas de diâmetro estão dentro do padrão esperado para esse ecossistema, ao passo que a altura é superior à maioria dos registros feitos em manguezais. A ocorrência das espécies $R$. mangle, A. schaueriana, L racemosa e A. germinans em diferentes regiões do país, evidencia semelhança florística com o manguezal da zona portuária de São Luís, reafirmando que essas espécies possuem larga distribuição geográfica no território brasileiro.

\section{REFERÊNCIAS}

ALMEIDA, V. C.; JUNIOR, C. C.; FEITOSA, F.; PASTOR, D.; MONTE, G. caracterização estrutural do manguezal do Rio Tabatinga, Suape, Pernambuco, Brasil. Tropical Oceanography, v. 42, n. 1, p. 37-47, 2014.

APG III. An update of the angiosperm phylogeny group classification for the orders and families of flowering plants: APG III. Botanical Journal of the Linnean Society, v. 141, n. 4, p. 399436, 2009.

BERNINI, E.; REZENDE, C. E. Variação estrutural em florestas de mangue do estuário do Rio Itabapoana, ES-RJ. Biotemas, v. 23, n. 1, p. 49-60, 2010.

BERNINI, E.; SANTOS, C. F. N. R.; OINTO, F. L.; CHAGAS, G. P.; REZENDE, C. E. Fitossociologia de florestas de mangue plantadas e naturais no estuário do Rio das Ostras, Rio de Janeiro, Brasil. Biotemas, v. 27, n. 1, p. 37-48, 2014.

BEZERRA, D. S. Análise dos manguezais submetidos a impactos ambientais decorrentes das atividades industriais no terminal portuário do Itaqui, Ilha de São Luís, Maranhão. 2005. 112 f. Monografia (Graduação em Ciências Aquáticas) - Universidade 
Federal do Maranhão, São Luís, 2005

BLOTTA, K. D.; QUINONES, E. M.; GIORDANO, F.; SANTOS, A. E. R.; FARRABOTI, E.; RIBEIRO, R. B. Fitossociologia comparativa de dois manguezais: Canal de Bertioga/SP e do estuário da Barra do Rio Una-Peruíbe-SP. Unisanta BioSciense, v. 5, n. 3, p. 271-282, 2016.

IBGE - Instituto Brasileiro de Geografia Estatística. Manual técnico em geociências: manual técnico da vegetação brasileira. 2 ed. Rio de Janeiro: Instituto Brasileiro de Geografia Estatística, 2012. $271 \mathrm{p}$.

IMAÑA ENCINAS, J.; SILVA, G. F.; TICCHETTI, I. Variáveis dendrométricas. Brasília: Universidade de Brasília, 2014. 102 p.

INMET - Instituto Nacional de Meteorologia. Clima: temperatura média anual e precipitação total anual. 2016. Disponível em: <http://www.inmet.gov.br/portal>. Acesso em: 02/09/2017.

LAMPRECHT, H. Silvicultura nos trópicos: Ecossistemas florestais e respectivas espécies arbóreas - possibilidades e métodos de aproveitamento sustentado. 2 ed. Eschborn: Instituto de Silvicultura da Universidade Gottingen, 1990. 343 p.

LONDE, V.; SALLES, D. M.; LEITE, M. G. P.; ANTONINI, Y. Estrutura da vegetação de mangue associada ao gradiente de inundação no litoral norte do Espírito Santo, Brasil. Árvore, v. 37, n. 4, p. 629637, 2013.

LOURENÇO, B. F.; BLOTTA, K. D.; PELLATIERO, V. M.; ROSENDO, A.; CRUZ, A. L.; LIMA, P. S.; JUNIOR, M. A. D. P.; FILHO, J. I. S.; GIORDANO, F.; MAGENTA, M. A. G. Avaliação da densidade de vegetais adultos encontrados no Manguezal localizado no Parque da Serra do Guararu, Guarujá, São Paulo, Brasil. Unisanta BioScience, v. 6, n. 1, p. 41-50, 2017.

MADI, A. P. L. M.; BOEGER, M. R. T.; LARCHER, L.; PELOZO, A.; SERENESKI, C.; REISSMANN, C. B.; PADIAL, A. A. Estrutura do componente de regeneração natural e arbóreo de dois manguezais no estado do Paraná. Ciência Florestal, v. 26, n. 1, p. 159-170, 2016.

MARTINS, M. B.; OLIVEIRA, T. G. de. Amazônia maranhense: diversidade e conservação. Belém: Museu Paraense Emílio Goeldi, 2011. 328 p.

MARTINS, P. T. A.; COUTO, E. C. G.; Delabie, J. H. C. Fitossociologia e estrutura vegetal do manguezal do Rio Cururupe (Ilhéus, Bahia, Brasil). Gestão Costeira Integrada, v. 11, n. 2, p. 163-169, 2011.

MCKEE, K. L. Soil physicochemical patterns and mangrove species distribution - reciprocal effects? Journal of Ecology, v. 81, n. 3, p. 477-487, 1993.

MOCHEL, F. R. Manguezais Amazônicos: status para a conservação e a sustentabilidade na zona costeira maranhense. In: MARTINS, M. B.; OLIVEIRA, T. G. de (Eds.). Amazônia maranhense: diversidade e conservação. Belém: Museu Paraense Emílio Goeldi, 2011. 328 p.

MUELLER-DOMBOIS, D.; ELLENBERG, H. Aims and methods of vegetation ecology. New York: Blackburn Press, 1974. 547 p.
OLIVEIRA, R. G.; TOGNELLA, M. M. P. Processo de colonização do manguezal do Rio Tavares por análise da estrutura de diferentes bosques. Brazilian Journal of Aquatic Science and Technology, $v$. 18, n. 1, p. 9-18, 2014.

PARAGUASSU, L. A. A.; SILVA, M. N. Caraterização fitossociológica de Porto de Sauípe, entre rios, Bahia. Diálogos e Ciência, v. 5, n. 12, p. 1-12, 2007.

PETRI, D. J. C.; BERNINI, E.; SOUZA, L. M.; REZENDE, C. E. Distribuição das espécies e estrutura do manguezal do rio Benevente, Anchieta, ES. Biota Neotropica, v. 11, n. 3. p. 107-116, 2011.

PMSL - Prefeitura Municipal de São Luís. Plano Municipal Integrado de Saneamento Básico (PMISB) de São Luís - MA: Diagnóstico da Situação dos Sistemas e da Prestação dos Serviços. 2011. Disponível em: <https://docgo.org/planomunicipal-integrado-de-saneamento-basico-pmisb-de-sao-luisma>. Acesso em: 17/08/2017.

SANTOS, T. O.; ANDRADE, K. V. S.; SANTOS, H. V. S.; CASTANEDA, D. A. F. G.; SANTANA, M. B. S.; HOLANDA, F. S. R.; SANTOS, M. J. C. Caracterização estrutural de bosques de mangue: estuário do São Francisco. Scientia Plena, v. 8, n. 4, p. 1-7, 2012.

SILVA, J. A. A.; PAULA NETO, F. P. Princípios básicos de dendrometria. 2 ed. Recife: Universidade Federal Rural de Pernambuco, 1979. $198 \mathrm{p}$.

SILVA, S. F. L.; SANTOS, M. A.; PINTO, F. L.; BERNINI, E. Fitossociologia de uma floresta de mangue adjacente a uma planície hipersalina no estuário do Rio Miriri, Paraíba, Brasil. Revista Nordestina de Biologia, v. 24, n. 2, p. 3-12, 2016.

SOARES, C. P. B.; PAULA NETO, F. de; SOUZA, A. L. de. Dendrometria e inventario florestal. 2 ed. Viçosa: UFV, 2011. 272 p.

Recebido em 12/10/2017 Aceito em 08/12/2017 